\title{
DE LOS TERRITORIOS LOCALES A LA INTERNACIONALIZACIÓN DE LO RELIGIOSO
}

\author{
Rabia Bekkar \\ Maitre de Conférences a I'Université de Paris X-Nanterre, Visiting professor, Center \\ for Contemporary Arab Studies, School of Foreign Service. Georgetown University, Washington DC
}

\begin{abstract}
A partir de un estudio de campo, la autora muestra las representaciones $y$ prácticas de los grupos socio-religiosos del barrio de Belleville en París donde la religión es el terreno privilegiado $-y$ menos cuestionada- de visibilidad de poblaciones con orígenes socioculturales diversos: judios loubavitchs, musulmanes tablighi y catolicismo popular. En este artículo se hace un análisis de los efectos estructuradores del espacio local inducidos por los lugares de culto o de afirmación identitaria (iglesia, sinagoga, mezquita, comercios, escuelas, librerías...), la privatización de espacios públicos y, a la vez, la publicización de unos movimientos religiosos que se inscriben progresivamente en unas complejas redes internacionales. Sobre un mismo territorio, estos diferentes grupos experimentan cotidianamente su mundialización.
\end{abstract}

$\mathrm{E}$

ste artículo extrae conclusiones de un trabajo sobre los «Territorios y aspecto público de las religiones en Belleville, la vulnerabilidad de los encuentros»'. La investigación se centra en las prácticas y representaciones de los grupos socioreligiosos de los barrios de la parte baja de Belleville (Bas-Belleville). La zona estudiada se sitúa entre los Distritos XI y XX de París y delimita un territorio bordeado por la calle des Pyrénées al noreste, las del Faubourg du Temple y Belleville al noroeste, las de Oberkampf, Ménilmontant y la avenida Parmentier al sureste. El bulevar de Belleville representa el eje central de la zona con tres estaciones de metro que comunican el barrio: «Belleville»,
«Couronnes»y «Ménilmontant». (Cf. mapa, páginas siguientes)

Hemos dado prioridad a la dimensión antropológica para comprender mejor las relaciones entre los grupos de población, insistiendo sobre todo en los modos de afirmación y reivindicación de identidad. El estudio se distingue de los trabajos sobre inmigración y religiones realizados en el campo de las ciencias políticas (Kepel, 1987) para inscribirse más bien en la línea de análisis propuesta por $P$. Simon en su tesis sobre demografía social (1994), donde rastrea la historia de la población de Belleville desde la perspectiva de la integración. 


\section{¿Cuál ha sido el objeto de investigación?}

Estudia las relaciones entre poblaciones de orígenes diversos, tanto en el ámbito de la práctica y los intercambios cotidianos, como de los procesos de representaciones recíprocos. Las construcciones de identidades y las estrategias de acción de los diferentes grupos -definidas según la adhesión religiosa, los papeles en el interior del grupo social así como por la gestión práctica de los modos de cohabitación y representación que desarrollan en la interacción social- constituyen los principales focos de interés de este estudio.

El espacio se considera aquí como la base para el establecimiento de relaciones significativas entre la materialidad de los lugares (la mezquita, la sinagoga, la iglesia, los comercios escondidos o halât $)^{2}$ y la existencia social. El estudio de campo ha delimitado estructuras espaciales en las cuales se reconoce una colectividad localmente ubicada. Los individuos sienten su pertenencia a la colectividad cuando identifican y definen un territorio. A este sentimiento de pertenencia se añade una referencia implícita al espacio de los demás. La co-presencia en un mismo territorio permite que los actores sociales presentes en espacios diferentes valoren su pertenencia en las representaciones del otro. Esta evaluación, positiva, negativa o neutra, es objeto de una constante negociación. Los grupos pueden también convertir su territorio en espacio de referencia: «no vivo en Belleville, pero vuelvo para el Kippour puesto que mis padres viven alli». Por consiguiente, estas referencias se organizan según una escala o umbrales simbólicos.

Hemos también especificado las modalidades espaciales, o sea, el encuentro entre la forma espacial y la forma de lo social mediante el cual los grupos sociales identifican su posición en un determinado territorio. El análisis propone una formalización de estas representaciones colectivas y pone en evidencia espacios privilegiados como mediadores de los posicionamientos de cada grupo. Localizar las fronteras y la organización material de los límites permite ubicar las estrategias de negociación para la convivencia en un determinado territorio. Para ello, hubo que considerar las acciones como una modalidad comunicativa de la cultura y de la religión.

La noción de interacción traduce esta idea fuerza de compenetración activa. Se entiende aquí como el conjunto de posiciones, situaciones y posturas que permiten, mediante los intercambios entre individuos y grupos, la transformación de una relación frente al otro. Esta relación puede formularse con palabras o bien manifestarse en escenas de la vida cotidiana (prácticas de resistencias, reformulaciones, reinterpretaciones, desviaciones etc.). La interacción vuelve al mismo tiempo el encuentro vulnerable; está, de hecho, constantemente sujeta a ajustes y justificaciones. (Goffman, 1973)

\section{El espacio de lo religioso}

Los ritos religiosos constituyen un espaciotiempo privilegiado para la afirmación de la permanencia en un grupo social; representan 
un momento clave de identificación con una sociedad ya que lo sagrado es, en nuestra opinión sin duda sustancial, aunque también relacional. Los ritos proporcionan sentido al vínculo social por la concentración de acontecimientos y relaciones que conllevan. Encarnando al mismo tiempo permanencia y cambio, los ritos pueden ser contemplados, según ha demostrado A. Van Gennep, como una vuelta al orden social o bien una creación de alternativas. (Da Matta, 1983). En esta investigación nos hemos centrado sobre todo en las prácticas a pequeña escala, prestando especial atención a las competencias de los actores sociales. De hecho, éstos se implican mucho en los lugares donde ésta en juego parte de su identidad (basado aquí principalmente en lo religioso).

Dado que en Belleville la religión es el eje central de la visibilidad social, los grupos se organizan alrededor de la tradición ortodoxa, popular o extremista. Sin embargo, como señala Gérard Lenclud, «la tradición no transmite la integridad del pasado; opera mediante un filtro» (Lenclud, 1987: 110123) Éste representa una especie de negociación entre las necesidades de autenticidad $\mathrm{y}$ de inserción en un entorno nuevo. Las referencias se renuevan desde la palabra y el ejemplo, repetidas y legitimadas cotidianamente por las creencias. Belleville, lugar tradicional de acogida de los emigrantes, muestra una marcada evolución desde principio de los años setenta. Se observa hoy una clara radicalización de lo religioso en este barrio y sus alrededores: el movimiento loubavitch ${ }^{3}$ gana terreno y se implanta materialmente, reemplazando paulatinamente la ortodoxia asquenazí; los tablighis ${ }^{4}$ desarrollan ahí sus actividades y pretenden densificar la red de mezquitas en el este parisino. La nueva capilla católica del bulevar de Belleville adapta igualmente sus discursos y actividades a este entorno.

La estructuración del espacio estudiado mediante los lugares de culto y los establecimientos de enseñanza es evidente. Para encontrar legitimidad en un espacio desvalorizado, los actores se sitúan en el campo menos discutido y de mayor reconocimiento: la religión. De ahí, se emprende una verdadera reconstrucción de la memoria colectiva tanto por parte de los judíos sefardíes como de los musulmanes. Los unos y los otros se alejan de las prácticas de origen y «transforman la religión en un emblema.» (Sayad, 1992) En Belleville, la religión permite a los actores trascender las culturas nacionales y re-territorializar la comunidad judía, católica o Umma musulmana.

\section{Unas ocupaciones variables del espacio público}

\section{Mapa del territorio}

Los territorios fueron estudiados como extensiones delimitadas por fronteras donde se entrelazan interacciones en lugares significativos. En la zona baja de Belleville, el espacio público se organiza en nichos espaciales donde el extranjero se vuelve sospechoso. La presencia policial es significativa y contribuye a desconfiar constantemente de peatones cuya apariencia es «normal». 
De ahí que el triángulo formado por las calles Couronnes-St Maur-Jean-Pierre Timbaud, configura una entidad relativamente cerrada e identificable como sector «musulmán». Los usuarios de este territorio se sirven de ello como referencia para organizar sus prácticas y conductas de acuerdo con las costumbres musulmanas. Este marco define el cambio de uso de ciertos comercios en el área circundante a las mezquitas. Por ejemplo, la compra de un bar en la calle Morand, frente a la mezquita Omar, por un miembro de la red $d a^{\prime} w a^{, 5}$ y su transformación en un café halâl (sin alcohol) convirtió a este establecimiento en un lugar afín al entorno. En este sentido, se puede uno preguntar sí la venta del restaurante Dar Djerba del bulevar de Belleville en el «barrio judío» fue negociada en función del entorno social y religioso.

En cuanto eje central del barrio, el bulevar de Belleville significa tanto un lugar de culto, de consumo como de paseo. Por tanto, dentro de este espacio público que acoge el mercado semanal, las prácticas no son fortuitas. El sur del bulevar de Belleville está, por ejemplo, más bien en manos de comerciantes musulmanes, el norte, de los judíos tunecinos, y la glorieta de Belleville (en el eje de la calle de Belleville), de los asiáticos. De modo que el carácter accesible y neutral asociado por definición a todo espacio público no siempre se ve aquí garantizado. Hemos observado, por ejemplo, situaciones de bloqueo en las calzadas durante los rezos del viernes o de l'Aïd, ${ }^{6}$ cerca de las mezquitas. Los comerciantes entorpecen el paso durante las fiestas judías y el Ramadán. En estas ocasiones su actividad invade las aceras y el dominio público; la construcción de tenderetes durante el Souc$\operatorname{coth}^{7}$, es un ejemplo entre otros. La compenetración de los territorios y la delimitación de las fronteras entre comunidades es así el resultado de un equilibrio complejo.

\section{Privatización de los espacios públicos}

La dialéctica entre el espacio interior y el espacio exterior de ciertos establecimientos públicos fue interesante de examinar, especialmente por las transformaciones de las prácticas en el paso de uno a otro. Por ejemplo, la mezquita -más que la sinagoga- aunque tiene todos los caracteres de un espacio público musulmán, se convierte en un espacio privado. Existen normas precisas de acceso. Cada individuo está sometido a preámbulos al entrar: las abluciones, quitarse los zapatos y cubrirse en el caso de las mujeres. Estas reglas dejan «ver una asimetría en la relación con los lugares así como con los objetos, acontecimientos y personas que se encuentran o van ahí» (Querré, 1992: 24) Hemos mostrado cómo se articula en la práctica lo sagrado y lo profano, lo puro y lo impuro, lo lícito y lo ilícito. Mediante estos cuestionamientos, hemos aclarado algunas estrategias de ocupación y consumo del espacio como ciertas maneras de administrar las interrelaciones y fronteras simbólicas.

El establecimiento de un espacio en un lugar privado mediante situaciones de interacción social pone de manifiesto el carácter de una estructura pública. Un individuo no puede auto-atribuirse una identidad musulmana, 
judía o católica para entrar en los diferentes espacios religiosos. Esta es una de las mayores dificultades de una investigación sobre religiones desde el «interior» puesto que, como señala E. Goffman, un individuo no es libre de optar por cualquier biografía, de elegir según las circunstancias, los encuentros y lugares, su pertenencia a categorías que le son ajenas. Prueba a la que hemos estado inmediatamente sometidos en cada encuentro con los responsables de la mezquita Omar o de la sinagoga de la calle Julien Lacroix, fue « $i$ Sois judíos? ¿Sois musulmanes?», como una manera de definir a priori al interlocutor y ponerlo en su sitio.

El retraimiento de las mujeres en el espacio privado remite a la misma problemática. Se organiza mediante la puesta en marcha de una serie de autorizaciones e prohibiciones que regulan su presencia en la calle. Los encuentros se vuelven delicados en ciertas zonas del espacio público de Belleville como en el caso de los confines de las mezquitas que las mujeres musulmanas evitan (salvo cuando van a rezar). Asimismo, no se paran en las terrazas de los cafés salvo quizás en las del bulevar, cerca del café-restaurante Bénisti (territorio más bien judío). En cambio, los alrededores de las escuelas o los parques son muy concurridos por las familias, siendo un ejemplo sintomático el jardín de Belleville.

\section{Puesta en escena y «publicitación» de las religiones}

Hemos estudiado las distintas puestas en escena corporales, vestimenta y lenguaje, maneras de presentarse y hablar, miradas y posiciones en el espacio. Por ejemplo, el estudio detallado de los modos de ocupación del bulevar de Belleville ha sido en este sentido instructivo. Los magrebíes se paran en pequeños grupos en el cruce de la calle Oberkampf y el bulevar de Belleville cerca de la estación de metro «Couronnes». De esa manera, las prácticas espaciales de la ciudad árabe parecen encontrar su ubicación en París. En cambio, avanzando hacía la estación «Belleville», son las terrazas de los cafés las que dominan el paisaje urbano con un «ambiente de la Goulette» ${ }^{8}$.

Los actores sociales exhiben un «modo de vivir» típico, por ejemplo, del Islam, mediante estas manifestaciones de «publicitación». En la calle Jean-Pierre Timbaud, los ritos, las fiestas, las prácticas que se refieren a la vestimenta, alimentación y al rezo, no son reducibles a una cultura privada de uso doméstico: el Islam ha afirmado significativamente su identidad ahí mediante su expresión pública. Los letreros están en árabe y los productos se ofrecen respetando el calendario de la Hégire. Se advierte una ruptura con la puesta en escena de los comercios magrebíes analizados por Anne Raulin (1986) en el Distrito XIII.

\section{Algunas ideas de conclusión}

El análisis del proceso de territorialización de las religiones en Belleville y de las formas de publicitación de sus prácticas conduce a tres conclusiones principales: 
El espacio público local está estructurado por instituciones religiosas que se inscriben dentro de redes internacionales;

Las estrategias empleadas son análogas, teniendo como objetivo principal reforzar los lazos comunitarios;

La construcción de una centralidad religiosa en un barrio popular se efectúa en contra del clero establecido.

\section{Una estructuración con base religiosa vinculada a organizaciones internacionales}

Dentro de las estrategias de organización del espacio local se pueden observar convergencias entre los responsables locales de las religiones del Libro. Los tres movimientos, tablighi, loubavitch y católico popular, pre-

110 tenden sacar la religión del espacio privado y hacerla visible en el espacio público.

Los medios empleados son evidentemente particulares a cada religión. El capellán de Notre Dame Réconciliatrice se para sistemáticamente en el pórtico de su capilla al final de los oficios y conversa con los feligreses o paseantes. Se aprovecha también del gusto actual por las procesiones. Hay que «mostrase» al mismo nivel que las otras religiones y manifestar la fe cristiana sin vergüenza. Pretende construir una visibilidad de lo católico a pesar de que su capilla tiene muy poca relevancia arquitectónica (según los lugareños, se parece a una piscina pública).

Para los tablighis, había que empezar por desplazar las salas de rezo de los sótanos y permitir a los musulmanes salir de la casi- clandestinidad en que estaban confinados. Esta operación de visibilidad está acompañada de una afirmación del sentimiento religioso del inmigrante musulmán en el espacio urbano. El objetivo abiertamente declarado de la asociación $F e$ y práctica es establecer una mezquita en todos los barrios donde haya musulmanes. Con toda evidencia, los sótanos de los edificios, los espacios apartados de las fábricas, las salas de reunión alquiladas no contribuían a integrar el Islam dentro del espacio público francés. Por consiguiente, han invertido en la zona baja de Belleville abriendo una mezquita en un inmueble que tiene una torre del lado del bulevar para luego comprar un edificio mayor que transformaron en mezquita. Esperan ahora ampliarlo, agregando plantas suplementarias. Los comercios alrededor de la mezquita se encuentran bajo influencia de esta presencia del Islam (libros, alimentos, vestimenta, responden los criterios musulmanes). De ese modo los musulmanes se construyen poco a poco un entorno islámico.

Una misma voluntad de exhibición se aprecia en el movimiento loubavitch. Cuando llegan a Belleville se encuentran con un barrio fuertemente marcado por la presencia sefardí, tierra de misión ideal para intentar rescatar a estos judíos que están equivocados en la observancia estricta de las reglas. Al principio, se trata de marcar diferencias con una presentación particular (sombrero, kippa, levitón negro, trenzas, barba tupida...), con prácticas alimenticias específicas (glat, cacher ${ }^{9}$ ), que necesitan sus comercios exclusivos del Beth Din loubavitch y ya no de los 
del Beth Din de París. Los loubavitch predican y practican la separación estricta entre mujeres y hombres en los espacios públicos, abren establecimientos de enseñanza propios, institutos ultra ortodoxos donde alumnos $y$ profesores se diferencian por la vestimenta. Construyen progresivamente en Belleville una segregación urbana fundada en un sistema comunitario que les protege contra toda influencia exterior.

En un mismo territorio, los diferentes grupos experimentan cotidianamente su mundialización. Se cocina con ingredientes que provienen de la India, Pakistán, Irán, del Maghreb, de Egipto, de la tradición centroeuropea o de Asia. También hay un zoco para la música y videos de todos esos países. Diferentes mundos coexisten en la vida local (Harvey, 1989).

«Belleville está en el centro del mundo», decía un comerciante amigo de los loubavitch. Sin haber podido encontrar una explicación clara a este fenómeno durante las entrevistas, es indiscutible que las tres corrientes religiosas estudiadas se inscriben en una perspectiva mundial. En cambio, las redes internacionales aparecen en ciertos documentos publicitarios como si emanarán de los lugares de culto o de sus asociaciones satélites, de las librerías o agencias de viaje, de los comercios o redes de encuentros.

Existen conexiones directas, por ejemplo, entre Belleville y Brooklyn, sede del movimiento loubavitch. Las idas y vueltas son frecuentes entre Belleville y Londres donde existe un importante centro tablighi. El bar Omar frente de la mezquita pertenece a un
Indio, país de origen del movimiento, aunque esté administrado por un tunecino.

Por su parte, el cura de la capilla católica comenta la situación de los católicos en Asia, minoritarios pero influyentes, y que acogen a una fuerte diáspora de Laos en su capilla.

Los actores sociales de las distintas religiones piensan sus acciones más allá de sus pertenencias nacionales. (Appaduraï, 1993: 411)

\section{Estrategias de reconquista similares}

En los tres casos, los objetivos están siempre delimitados con precisión: no se trata de convertir a los miembros de otras comunidades religiosas puesto que el proselitismo ofensivo ya no es admisible. «Lo que cuenta, es la oveja perdida y no las que están en la manada», afirma el sacerdote católico.

La misión evangelizadora de la iglesia católica en los ambientes populares de Belleville, parece centrada hoy en promover el compartir y la comprensión mutua. Las actividades de la capilla están abiertas a todos, especialmente a africanos y asiáticos, que se muestran muy activos. La referencia principal es la obra del Padre de Foucauld que quería ser un «fraile universal».

Los tablighis y loubavitch entienden el rescate de las ovejas «perdidas» como una misión fundamental del practicante. Para ello recorren los barrios, mercados, todos los sitios donde puedan convencer a sus correligionarios a juntarse con ellos en los lugares de culto y respetar las vestimentas conforme a sus prácticas. Los jóvenes son un objetivo 
prioritario y por eso han organizado, de un modo más o menos' formal, cursos de iniciación y perfeccionamiento (enseñanzas en las mezquitas, socialización de los adolescentes delincuentes en un espacio específico fuera de París para el tablighi y construcciones de escuelas para los arrepentidos loubavitch).

Mediante una especie de emulación recíproca, estas prácticas se ven reforzadas por la presencia de las tres religiones monoteístas en un mismo territorio. Un católico practicante nos explica que Belleville se ha transformado en el único barrio de París donde retrocedía el laicismo. Todas las instituciones religiosas desarrollan actividades caritativas mediante asociaciones que están bajo su esfera de influencia o mediante iniciativas privadas de inspiración religiosa. Por ejemplo, la Chorba para todos, Shalom, Fraternidad o Auxilio católico organizan distribuciones de alimentos que son, en principio, independientes de la religión de los beneficiarios.

Sin embargo, esta competencia favorece el reagrupamiento comunitario de unos frente a otros que se vive simultáneamente como una relación de socios: «Somos hermanos», «Respetamos el mismo Libro», pero se percibe también como un riesgo. Pese a todo, los contactos entre responsables religiosos son poco frecuentes.

Los fervientes de las tres grandes religiones presentes en Belleville parecen diferenciarse por sus opciones políticas. Todos parecen haberse dado cuenta de las prebendas asociadas al lobbying ante los representantes políticos.
Sin haber efectuado una investigación sistemática sobre las opciones políticas, un análisis de los discursos deja entrever que los loubavitch reivindican opciones de «derecha» mientras que los tablighis se asocian más bien con las de «izquierda». La posición de los primeros, al menos como movimiento estructurado, ha sido afirmada por una llamada de su Rabino a favor de la reunión «Para la República» en las últimas elecciones. A cambio, el Ayuntamiento de París y el Consejo Regional les ha apoyado claramente en sus diversos proyectos inmobiliarios, especialmente en el Distrito XX.

Respecto a la asociación Foi et Pratique (Fe y práctica), parece que su postura ha evolucionado desde los trabajos realizados por Gilles Kepel en 1986. En esa época el movimiento tablighi tenía poco peso en la escena política francesa. (Kepel, 1991: 253) La situación ha cambiado desde entonces: muchos jóvenes nacidos en Francia se han afiliado al movimiento y su voto cuenta, tanto a escala local como nacional. En el este de París, por ejemplo, los proyectos de construcción de un Instituto Islámico, o a escala menor, el proyecto de ampliación de la mezquita Omar, han sido presentados a los candidatos de izquierda antes de las elecciones legislativas. El tablighi no representa ya sólo una simple alternativa a los movimientos islámicos radicales que operaban en el campo social y estaban poco presentes en la escena política; su intención es ahora posicionarse firmemente en el campo de la política y de lo público. 


\section{La construcción de un centrismo religiosa ortodoxa}

Las nuevas formas de organización se desarrollan a menudo en oposición más o menos abierta a las instituciones religiosas establecidas. Para los tablighis, por ejemplo, los representantes de la Mezquita de París están demasiado volcados hacía los Estados musulmanes y no defienden suficientemente los intereses musulmanes en Francia. Las prácticas y creencias difundidas por la asociación Fe y Práctica parecen estar en oposición con la tradición sunnita. Más política y popular, menos sabia, la $d a^{\prime} w a^{\prime}$ rompe con el Islam de los países de origen. El Malékisme (una de las escuelas sunnita), que constituye el fundamento de la práctica religiosa del Magreb, pierde paulatinamente influencia con la llegada del tropismo Hanbaliste ${ }^{10}$ (rigorista y cerrado a toda innovación) venido de Oriente.

El paralelo con los loubavich es sorprendente: proveniente de una corriente religiosa de Europa oriental, reúnen en Belleville, principalmente a sefardíes. La base popular de este movimiento pietista es idéntica: rechazo a la erudición, aplicación estricta de los mandamientos, misión apostólica para reconducir a los fieles al recto camino. Los rabinos del barrio, muchas veces procedentes de la escuela rabínica de Túnez, critican los métodos empleados por los loubavitch y especialmente las formas de «reclutamiento» en el espacio público pero sin poder condenarlos con facilidad abiertamente. El Consistorio y el CRIF 11 mantienen relaciones muy ambiguas con el movimiento loubavitch (Trigano, 1996).
En el barrio estudiado, los territorios se organizan alrededor de los lugares de culto. En torno a estos polos de atracción se crean estructuras que acompañan y afirman la religión: escuelas, librerías, comercios de alimentos lícitos. Las fronteras entre estas diferentes influencias, temporales o perennes, se negocian. El espacio social se construye actualmente sin conflictos y en él la religión cumple el papel de referente para inculcar respecto al otro. Para cada una de las comunidades del barrio, sentirse como una minoría asegura en la práctica una especie de equilibrio puesto que ningún grupo se considera dominante. Aunque esta situación parece lógica a musulmanes y judíos, para los católicos (hija mayor de la Iglesia cristiana) es de cierta manera una paradoja. Sin embargo, todos los entrevistados estiman que las circunstancias son más bien cómodas y permiten «vivir juntos»: aunque la apuesta sea por la visibilidad, ésta no debe hacer sombra al otro.

La revitalización del espacio público de Belleville, vulnerable a causa de estas aspiraciones religiosas, deja subsistir nichos de mezcla social y étnica. El mercado es el mejor ejemplo, pero también se puede observar en ciertas terrazas del bulevar de Belleville o en las farmacias.

No obstante, el comunitarismo creciente y el afán simultáneo de aislarse pueden llegar a desembocar en la creación de comunidades cerradas, especialmente en el caso de los loubavitch, con todos los riesgos de restricción y accesibilidad al acceso del espacio público que ello supone. 


\section{BIBLIOGRAFÍA CITADA}

Da Matta, Roberto, Carnavals, bandits et héros. Ambigüités de la société brésilienne, París, Seuil, 1983.

Goffman, Erving, La mise en scène de la vie quotidienne, 2 tomos, París, 1973.

Kepel, Gilles, Les banlieues de l'Islam. Naissance d'une religion en France, París, Seuil, 1987.

Lenclud, Gérard, «La tradition n'est plus ce qu'elle était», en Terrain, núm. 9, 1987, pp.110-123.

Raulin, A., «Mise en scène des commerces maghrébins parisiens», en Terrain, núm. 7, 1986, pp. 24-33.

Sayad, Abdelmalek, L'immigration ou les paradoxes de l'altérité, Bruxelles, de Boeck-Université, 1992.
Simon, Patrick, La société partagée: relations interethniques et interclasses dans un quartier en Rénovation. Thèse en Démographie sociale, París, EHESS-Université de París VII, 1994.

Trigano, Shmuel, Un exil sans retour. Lettres à un juif égaré, París, Stock, 1996.

Harvey, David, The Condition of posmodernity: An inquiri into the origins of culture change, Oxford, Blakwell, 1989.

Appadurai, Arjun, «Patriotism and its future», en Public Culture 5 (3), 1993, p. 29.

\section{NOTAS}

1 Investigación realizada bajo la dirección de Rabia Bekkar, IPRAUS-FAS, 1997.

${ }^{2}$ Halât: palabra árabe que significa lícito, puro, permitido. Designa especialmente la carne cuyo consumo está autorizado si el animal ha sido sacrificado según los ritos musulmanes.

${ }^{3}$ Loubavitch: es un movimiento hassidico que está vinculado a la tradición HaBaD, iniciales de las palabras «Conocimiento, inteligencia, sabiduría». El maestro espiritual de este movimiento es el Rabí loubavitch que reside en Brooklyn.

4 Tagligh: literalmente significa «Proclamación del Islam». Proselitismo interior islámico al cual se dedican los miembros de la jama 'at tabligh, movimiento fundado en los años veinte en la India que se basa en la simplicidad de los mensajes, la cohesión del grupo y el intenso compromiso personal de los seguidores.

5 Da'wa': palabra árabe que significa literalmente «llamada a». Nombre genérico dado a todas las actividades de apostolado (predicación, conversaciones, giras, conferencias, enseñanza religiosa), en particular, en el movimiento Tagligh.

${ }^{6}$ Aijd el Kebir: fiesta religiosa de los musulmanes que conmemora el sacrificio de Abraham durante la cual todo jefe de familia tiene que sacrificar un cordero. Aid el Sghir: fiesta que celebra el fin del Ramadán.

"Souccoth: en hcbreo, «cabañas». Fiesta que conmemora la travesía de los Hebreos durante cuarenta años en el desierto. Se prescribe residir en una cabaña cuyo techo tiene que ser cubierto por ramas, recuerdo simbólico de la vivienda frágil que fue la de los Hebreos durante su marcha hacía la tierra prometida.

${ }^{8}$ La Goulette es un barrio al borde del mar, cerca del centro de la ciudad de Túnez donde vivía una importante comunidad judía antes de la independencia del país.

Cacher: significa literalmente «lícito, conforme». Aplicación de reglas de consumo para el judío practicante. Las carnes de cerdo, de caballo y de conejo son consideradas impuras para el consumo. En cuanto a las otras carnes, el animal debe ser sacrificado según un ritual para poder ser «cacher». Con el fin de que la «cacherización» sea completa, se debe remojar la carne en agua y salarla muchas veces para limpiarla de sangre. Está también prohibido de comer alimentos de tipo cárnico y lácteo en una misma comida; según la prescripción bíblica: «no cocinarás el cabrito en la leche de su madre».

${ }^{10}$ Hanbalisme: una de las escuelas de jurisprudencia del Islam sunnita que se aplica en Arabia y en ExtremoOriente.

"CRIF: Consejo Representativo de las Instituciones judías de Francia, creado en 1943. Tenía como misión defender ante las instancias gubernamentales, los partidos políticos y la opinión pública, los derechos de la comunidad judía. 